\title{
Evaluation of the association between gastric cancer and plasma selenium in Zambian adults: a case-control study
}

\author{
Kanekwa Zyambo ${ }^{1}$, Paul Kelly ${ }^{1,2}$ and Violet Kayamba ${ }^{1}$ \\ ${ }^{1}$ Tropical Gastroenterology and Nutrition Group, University of Zambia School of Medicine, PO Box 50398, Lusaka 10101, Zambia \\ ${ }^{2}$ Blizard Institute, Barts \& The London School of Medicine and Dentistry, Queen Mary University of London, 4 Newark Street, London E1 2AT, UK
}

\begin{abstract}
There is some evidence that Selenium (Se) is protective against gastric carcinogenesis, but these data are inconsistent. With a predicted increase in gastric cancer cases in Africa over the next 20 years, there is an urgent need to identify strategies that could be employed to prevent the surge. The objective of our study was to investigate the association between gastric cancer and plasma Se levels in Zambian adults. Our method used a case-control study with cases having either confirmed gastric cancer or premalignancies and controls having none. In addition, we measured antibodies against Helicobacter pylori and human immunodeficiency virus. Data were analysed with Stata 15 software using standard statistical methods. Using a normal reference range for Se of 0.9-1.9 $\mu \mathrm{mol} / \mathrm{L}$, 140/159 (88\%) study participants had Se deficiency. Plasma Se levels were similar in all the three groups; 0.33 (interquartile range (IQR) $0.14-0.64) \mu \mathrm{mol} / \mathrm{L}$ for patients with gastric cancer, 0.38 (IQR 0.21-0.60) $\mu \mathrm{mol} / \mathrm{L}$ for premalignant lesions and 0.28 (IQR $0.14-0.64) \mu \mathrm{mol} / \mathrm{L}$ in controls, ( $p$-values $=0.35$ and 0.34 , respectively). In conclusion, we found no association between plasma Se levels and gastric cancer or premalignant lesions among adult Zambian adults.
\end{abstract}

Keywords: gastric cancer, atrophy, intestinal metaplasia, Selenium

\section{Introduction}

Selenium (Se) is an essential micronutrient which exerts its biological activity through selenoproteins [1]. It is a potent antioxidant and anti-inflammatory agent and has therefore been investigated in several disease conditions, including cancer [2, 3]. However, excessive amounts of Se have also been shown to have detrimental health effects [4].

Gastric cancer is one of the leading causes of cancer-related mortality worldwide. In 2020, there were over a million cases of gastric cancer, with 768,793 related deaths [5]. It is estimated that by 2040 cases of gastric cancer will have increased by over $60 \%$ [5]. The role of micronutrients in gastric cancer development has been evaluated by several investigators with inconsistent conclusions [6]. With its known antioxidant properties, Se is thought to be protective against gastric cancer [7, 8], and low levels have been reported in gastric cancer patients $[9,10]$. Analysis from the NutriNet-Santé cohort showed that higher Se

Correspondence to: Violet Kayamba Email: viojole@yahoo.com

ecancer 2022, 16:1351

https://doi.org/10.3332/ecancer.2022.1351

Published: $27 / 01 / 2022$

Received: 23/03/2021

Publication costs for this article were supported by ecancer (UK Charity number 1176307).

Copyright: (c) the authors; licensee ecancermedicalscience. This is an Open Access article distributed under the terms of the Creative Commons Attribution License (http:// creativecommons.org/licenses/by/4.0), which permits unrestricted use, distribution, and reproduction in any medium, provided the original work is properly cited. 
intake was associated with a decreased digestive cancer risk [11]. In addition, Se was also reported to have a role in reducing the effects of known carcinogens [12]. With continued advances, there also is evidence that Se could have a role in gastric cancer therapy [13, 14].

Diet is the major source of Se and availability in plant-based foods varies depending on the amounts present in the soil [4, 15]. Similarly, for animal products, such as milk and eggs, the levels depend on quantities in feeds used to raise the animals [4]. These factors contribute to observed population variations in Se levels in different parts of the world [4]. A recently conducted Cochrane review found no evidence that increasing Se intake through diet or supplementation prevented cancer in humans [16]. It is thought that incremental doses of Se would be beneficial against cancer [17], but a study evaluating tissue accumulation of Se showed that levels were higher in gastric cancer tissues than non-cancerous ones [18]. With this work on the influence of Se on carcinogenesis, it remains unclear what Se levels would be most beneficial for cancer prevention.

The burden of gastric cancer appears to be increasing in sub-Saharan Africa, but there are limited data implicating micronutrients such as Se in this predominately low resource region. Se status in southern/central Africa is known to be poor [15], so we took the opportunity of a recently completed case-control study of gastric cancer to test the hypothesis that gastric cancer may be related to Se deficiency.

\section{Methods}

This was a case-control study conducted at the University Teaching Hospital in Lusaka, Zambia. It was part of a larger study evaluating risk factors for gastric cancer in a Zambian population [19]. The study participants were enrolled from among patients referred for esophagogastroduodenoscopy (OGD). All patients signed informed consent to participate. Cases were patients either with histologically confirmed gastric adenocarcinoma (gastric cancer) or premalignant lesions (atrophy, intestinal metaplasia or dysplasia). Controls were patients who presented for OGD but were found to have no gastric cancer or premalignant lesions. Patients with a prior history of gastric cancer treatment were excluded from the study. The study was approved by the University of Zambia Biomedical Research Ethics committee, reference number 000-03-16.

\section{Study procedure}

OGD was carried out on the patients under light sedation as previously described [19]. At least six biopsies were taken from lesions suspected of being malignant. Biopsies were also obtained from patients without any visible lesions: two each from the antrum, incisura and body along the greater curvature. This was done to check for the presence of gastric premalignant lesions. Biopsies were immediately placed in buffered formalin-saline and sent for histopathology. A technician processed these biopsies using standard methods and histological diagnoses were carried out by an experienced pathologist. Peripheral blood (plasma later extracted) was collected and stored at $-80^{\circ} \mathrm{C}$ for further analysis of Se levels. Basic clinical characteristics were obtained using interviewer-administered questionnaires. The month of patient recruitment was recorded and categorised into the three seasons in Zambia: cold and dry (April-July), hot and dry (August-October) and hot and wet (November-March).

\section{Measurement of plasma Se}

Plasma Se levels were measured using the Optima DV 7000 (Perkin Elmer, Midrand, South Africa). Following collection, blood was centrifuged at $856 \mathrm{~g}$ for 15 minutes at $4^{\circ} \mathrm{C}$ to extract plasma, then stored in a $-80^{\circ} \mathrm{C}$ freezer. Three triplicates were carried out per sample. Diluent containing $2 \%$ nitric acid, $3 \mathrm{M} \mathrm{HCl}$ and $1 \%$ Triton was used to digest the sample. To create a standard curve, five working standard solutions ranging from 0.5 to $2.5 \mu \mathrm{mol} / \mathrm{L}$ (PerkinElmer Pure Instrument Calibration Standard 4-N930021) were used. Seronorm L-1 (SERO AS 0903106) $1: 9 \mathrm{v} / \mathrm{v}$ with diluent and a pooled plasma sample were used as quality control which was rerun after every ten samples. Plasma samples were diluted (1:9 v/v) with a diluent. Instrument working conditions were set at wavelength $196.026 \mathrm{~nm}$, plasma gas flow $1.5 \mathrm{~L} /$ minute, auxiliary gas flow $0.2 \mathrm{~L} /$ minute, nebuliser gas flow $0.6 \mathrm{~L} /$ minute, RF Power $1450 \mathrm{~W}$ and peristaltic pump flow rate $1.8 \mathrm{~mL} / \mathrm{minute}$.

\section{Measurement of antibodies against Helicobacter pylori (HP) and human immunodeficiency virus (HIV)}

Testing for HIV antibodies was done using Uni-Gold ${ }^{\text {TM }}$ rapid diagnostic kits (Trinity Biotech, Wicklow, Ireland). IgG antibodies against HP were quantitatively measured in $\mathrm{U} / \mathrm{mL}$ with enzyme-linked immunosorbent assay by Abcam (ab108736), Cambridge, UK. 


\section{Statistical analysis and sample size estimation}

We powered the study to determine a difference between gastric cancer cases and controls. We used proportions from an Iranian study in which they reported Se levels of $111.6 \pm 27.7 \mu \mathrm{g} / \mathrm{L}$ in gastric cancer patients and $129.9 \pm 32.1 \mu \mathrm{g} / \mathrm{L}$ in controls [10]. With an $80 \%$ power and alpha of 0.05 , we needed at least 44 patients in each group.

All continuous variables were summarised using medians and interquartile ranges as they were non-parametric, and proportions were computed for categorical data. Normality was tested using the Shapiro-Wilk test.

Two-way analyses were employed to look for associations between gastric cancer or premalignant lesions and exposures of interest using the Kruskal-Wallis test for multiple values and Fisher's exact test for binary variables. Confidence intervals at $95 \%$ were used with $p$-values less than 0.05 being considered statistically significant. A stepwise logistic regression analysis was carried out to evaluate associations while adjusting for possible confounders. Data were analysed using STATA version 15 (College Station, TX, USA).

\section{Results}

Over 21 months, we enrolled 159 patients. Among them, 56 (35\%) had gastric cancer and 18 (11\%) had gastric premalignant lesions. These patients were compared to 85 (54\%) controls. Of those with premalignant lesions, $6 / 18$ (32\%) had atrophy without intestinal metaplasia and $12 / 18(68 \%)$ had atrophy with intestinal metaplasia. None of the patients had dysplasia.

The median age was 62 years (IQR $=52-72$ years) for gastric cancer patients, 56 years (IQR $=40-69$ years) for those with premalignant lesions and 56 years (IQR $=41-60$ years) for the controls. There was a statistically significant difference in age between controls and patients with gastric cancer $(p<0.001)$ but not premalignant lesions ( $p=0.33$; Table 1$)$. Similarly, gastric cancer patients had a significantly low body mass index (BMI). HIV-positive status was similar in all the groups at about $20 \%$ (Table 1).

\section{Plasma Se comparison among the three patient groups (gastric cancer, premalignant lesions and controls)}

The median plasma levels of Se were $0.33(\mathrm{IQR}=0.14-0.64) \mu \mathrm{mol} / \mathrm{L}$ in gastric cancer patients, while it was $0.38(\mathrm{IQR}=0.21-0.60) \mu \mathrm{mol} / \mathrm{L}$ in controls, a difference that was not statistically significant $(p=0.35)$. The median level in patients with premalignant lesions was 0.28 (IQR $=$ $0.14-0.64) \mu \mathrm{mol} / \mathrm{L}$, which similarly was not significantly different from the Se level in controls $(p=0.34$; Figure 1). Using a normal reference range for Se of 0.9-1.9 $\mathrm{mol} / \mathrm{L}$ [20], 49/56 (88\%) gastric cancer patients, 16/18 (89\%) patients with premalignant lesions and 75/85 (88\%) controls had low Se levels. Low serum Se was not associated with either gastric cancer $(\mathrm{OR}=0.9 ; 95 \% \mathrm{Cl}=0.3-3.1, p=1.0)$ or premalignant lesions (OR $=1.1 ; 95 \% \mathrm{Cl}=0.2-10.9, p=1.0)$. Dividing the Se levels into four quartiles, there was no difference between the two groups of cases and controls (all $p$-values > 0.05; Table 2). The measured Se levels were lowest in the hot and dry seasons (Figure 2), but this had no influence on the above-mentioned comparisons. A stepwise logistic regression model, including the confounders age, sex, type of patient (gastric cancer or premalignant lesion and controls), season, BMI, HIV status and HP antibodies, did not show any association between gastric cancer or premalignant lesions and low Se levels (all $p$-values $>0.05$ ). Separate models were employed for gastric cancer cases and those with premalignant lesions.

\section{Discussion}

The role of Se in gastric carcinogenesis is not clear. In this study, we report a high proportion of low Se levels among Zambian adults with no association with gastric cancer or premalignant lesions.

It is known that micronutrient deficiencies are commonest in communities with poor dietary diversity [21], which includes many low-income African countries [15]. In Malawi, for example, a representative population of 2,761 people revealed Se deficiency prevalence of about $60 \%$ [22]. Another study, also from Malawi, estimated that more that 50\% of the households were at risk of Se deficiency [23]. Gastric cancer, despite its predicted rise in cases over the next 20 years, is not among the most prevalent cancers in Africa [5], which strengthens the argument that Se deficiency might not necessarily be a major contributing aetiological factor. However, carrying out comprehensively designed 
high-quality studies on gastric cancer in a low resource setting is limited by scantly endoscopy services, poor expertise and a generally limited financial investment. Similarly, studying Se intake or estimating its status requires additional resource mobilisation. The main source of Se is dietary [24], but accurately predicting the status from oral intake is a challenging [25]. Measurement of Se can be done from plasma, erythrocytes, selenoproteins and glutathione peroxidase activity [26], and there is recent evidence that urine measurements can also give reliable population level estimates [27].

Table 1. Summary of the characteristics of enrolled patients in three groups: gastric cancer, gastric premalignancy and controls.

\begin{tabular}{|c|c|c|c|c|c|c|}
\hline Characteristic & $\begin{array}{l}\text { Controls } n(\%) \\
\quad n=85\end{array}$ & $\begin{array}{l}\text { Gastric cancer } \\
n(\%), n=56\end{array}$ & $p$-value & $\begin{array}{l}\text { Controls } n(\%), \\
\quad n=85\end{array}$ & $\begin{array}{c}\text { Gastric premalignancy } \\
n(\%), n=18\end{array}$ & $p$-value \\
\hline $\begin{array}{l}\text { Sex } \\
\text { Male } \\
\text { Female }\end{array}$ & $\begin{array}{l}39(46 \%) \\
46(54 \%)\end{array}$ & $\begin{array}{l}24(43 \%) \\
32(57 \%)\end{array}$ & 0.73 & $\begin{array}{l}39(46 \%) \\
46(54 \%)\end{array}$ & $\begin{array}{c}7(39 \%) \\
11(61 \%)\end{array}$ & 0.61 \\
\hline $\begin{array}{l}\text { Age group (years) } \\
\text { Less than } 30 \\
30-44 \\
45-60 \\
\text { More than } 60\end{array}$ & $\begin{array}{c}3(4 \%) \\
28(33 \%) \\
31(36 \%) \\
23(27 \%)\end{array}$ & $\begin{array}{c}1(2 \%) \\
6(11 \%) \\
18(32 \%) \\
31(55 \%)\end{array}$ & $<0.001$ & $\begin{array}{c}3(4 \%) \\
28(33 \%) \\
31(36 \%) \\
23(27 \%)\end{array}$ & $\begin{array}{c}0(0 \%) \\
7(39 \%) \\
4(22 \%) \\
7(39 \%)\end{array}$ & 0.62 \\
\hline $\begin{array}{l}\text { BMI }\left(\mathrm{kg} / \mathrm{m}^{2}\right) \\
\text { median }(\mathrm{IQR})\end{array}$ & $24(21 \%-27 \%)$ & $18(16 \%-21 \%)$ & $<0.001$ & $24(21 \%-27 \%)$ & $26(23 \%-29 \%)$ & 0.45 \\
\hline HP serology, U/mL & $120(92 \%-157 \%)$ & $126(95 \%-155 \%)$ & 0.95 & $120(92 \%-157 \%)$ & 96 (88\%-159\%) & 0.41 \\
\hline $\begin{array}{l}\text { HIV antibodies } \\
\text { Positive } \\
\text { Negative }\end{array}$ & $\begin{array}{l}19 \text { (23\%) } \\
65 \text { (77\%) }\end{array}$ & $\begin{array}{l}11(21 \%) \\
42(79 \%)\end{array}$ & 0.84 & $\begin{array}{l}19(23 \%) \\
65(77 \%)\end{array}$ & $\begin{array}{c}4(22 \%) \\
14(78 \%)\end{array}$ & 1.00 \\
\hline
\end{tabular}

a The Kruskal-Wallis and Fisher's exact tests were used for hypothesis testing (associations between various factors and gastric cancer or premalignant lesions)

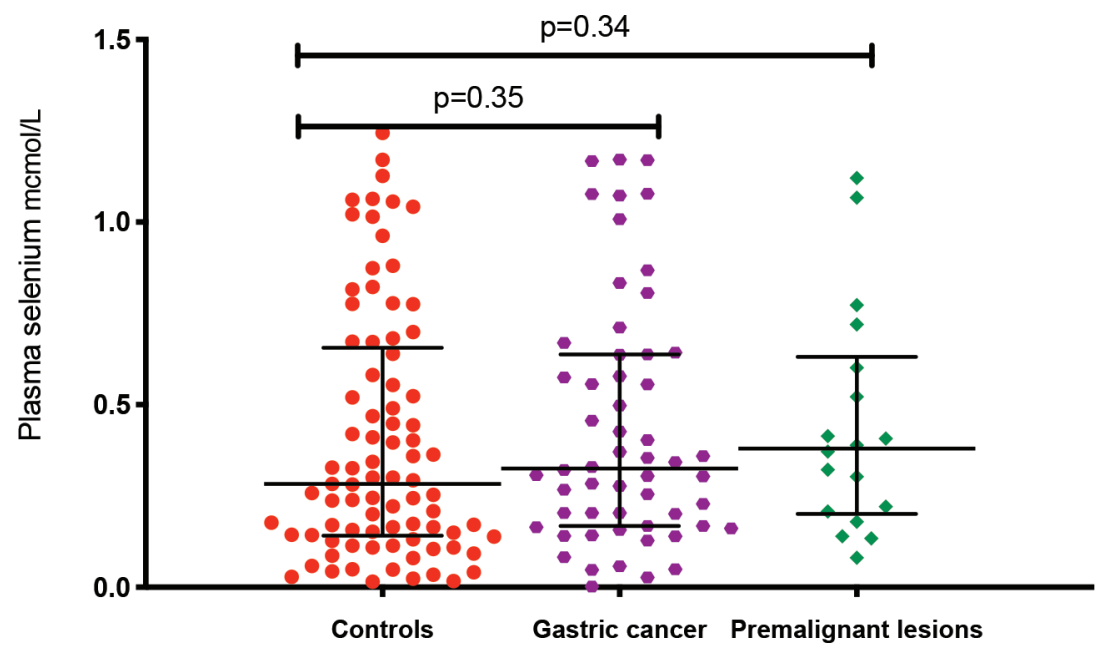

Figure 1. Plasma Se levels in the three patient groups: gastric cancer, premalignacy and controls. *Test for association computed using the Kruskal-Wallis test. ${ }^{* *}$ Error bars represent median with interquartile ranges. 
Table 2. Evaluation of Se levels in gastric cancer, gastric premalignancy and controls divided into quartiles.

\begin{tabular}{|l|c|c|c|c|c|}
\hline $\begin{array}{c}\text { Se }(\mu \mathrm{mol} / \mathrm{L}) \text { levels in } \\
\text { quartiles }\end{array}$ & $\begin{array}{c}\text { Controls, median } \\
(\mathrm{IQR})\end{array}$ & $\begin{array}{c}\text { Gastric cancer, } \\
\text { median (IQR) }\end{array}$ & $\begin{array}{c}p \text {-value (comparison for } \\
\text { gastric cancer and controls) }\end{array}$ & $\begin{array}{c}\text { Gastric premalignancy, } \\
\text { median (IQR) }\end{array}$ & $\begin{array}{c}p \text {-value (comparison for } \\
\text { premalignancy and controls) }\end{array}$ \\
\hline First quartile & $0.1(0.04-0.1)$ & $0.07(0.05-0.2)$ & 0.72 & $0.1(0.08-0.1)$ & 0.35 \\
\hline Second quartile & $0.2(0.2-0.3)$ & $0.2(0.2-0.3)$ & 0.61 & $0.2(0.2-0.3)$ & 0.94 \\
\hline Third quartile & $0.4(0.4-0.5)$ & $0.4(0.3-0.6)$ & 1.00 & $0.4-0.5)$ & 0.82 \\
\hline Fourth quartile & $0.9(0.8-1.1)$ & $0.9(0.7-1.1)$ & 0.70 & $0.7 .1)$ & 0 \\
\hline
\end{tabular}

a The Kruskal-Wallis test was used for hypothesis testing (associations between Se levels in four quartiles and gastric cancer or premalignant lesions)

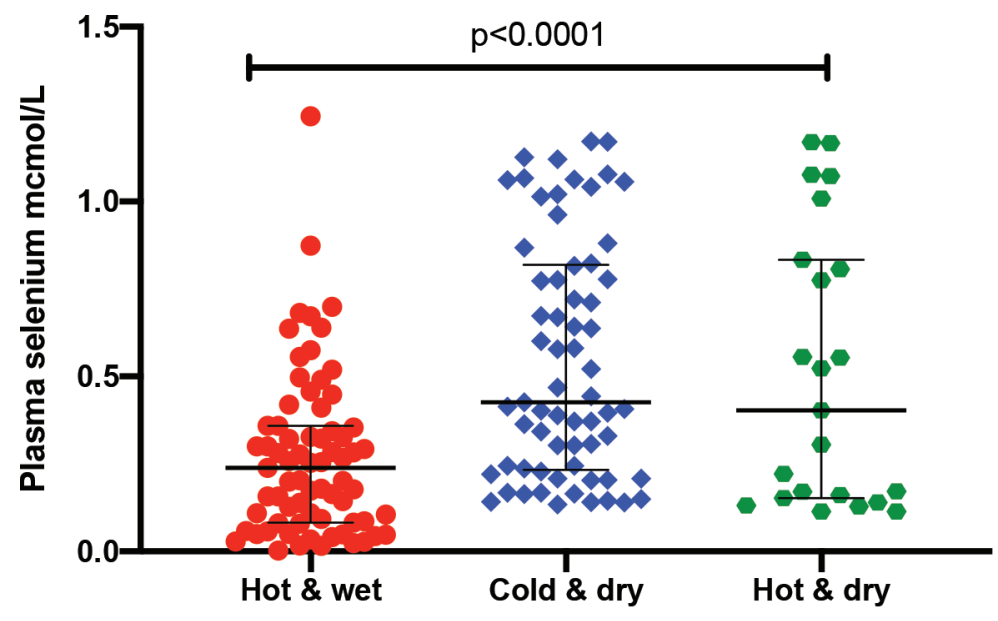

Season

Figure 2. Plasma Se by season: hot and wet is from November to March; cold and dry is from April to July; and hot and dry is from August to October. *Test for association computed using the Kruskal-Wallis test. ${ }^{* *}$ Error bars represent median with interquartile ranges.

HP is a major risk factor for gastric cancer so we analysed its potential link to plasma Se levels. Our previous work did not demonstrate any association between serological measures of HP infection and gastric cancer or its virulence factor CagA [28] and here we explored the possibility of a synergistic role of Se and HP. The role of Se on HP virulence has not been defined, but there are reports of differential Se statuses in direct comparisons between inhabitants of high and low gastric cancer incidence regions [29]. Studies evaluating this subject did not find an association between HP and Se [30, 31].

Se plays a role in immune system function and consequently the progression of HIV disease [32]. Patients included in this study were selected from among those coming to the hospital, resulting in a higher prevalence than the national figures for Zambia. We found no association between HIV and Se levels in this study, but had also previously reported no link between gastric cancer and HIV infection [28]. Our finding of seasonal variations in Se levels could be a reflection of fluctuations in Se intake, which is largely dependent on consumed food. Generally, the measurement of plasma Se is an indicator of short-term status and would therefore be affected by seasonal dietary changes [33]. Using logistic regression, we were able to show that seasonal Se changes in our patients did not influence our overall conclusion.

To the authors' knowledge, this is the first study evaluating the absence of link between gastric cancer and plasma Se in Zambia. However, the study has some limitations. Firstly, plasma measurements do not allow for long-term assessment of Se status, which is what would be most informative as carcinogenesis in not an acute process. Secondly, the study was powered to detect a difference for gastric cancer patients but not those with premalignant lesions. Therefore, we could have missed an effect with the latter group. 


\section{Conclusion}

In conclusion, there was a high proportion of low Se levels in the study participants. We found no association between plasma Se and gastric cancer or its premalignant lesions. It is, therefore, unlikely that Se is a driver for gastric carcinogenesis in this population.

\section{List of abbreviations}

HIV Human immunodeficiency virus

Se Selenium

\section{Acknowledgments}

The authors acknowledge the efforts made by technician Anglin Hamasuku in preparing biopsy samples and Dr Aaron Shibemba (Head of the Pathology department at the University Teaching Hospital in Lusaka) for evaluating the biopsies.

\section{Conflicts of interest}

None of the authors have any conflicts of interest to declare.

\section{Funding}

The research reported in this publication was partially supported by the Fogarty International Centre of the United States National Institutes of Health (NIH) under award number D43 TW009744 and the U.S Civilian Research and Development Foundation (CRDF Global) provided additional funding award number DAA3-16-62699-1. The content is solely the responsibility of the authors and does not necessarily represent the views of the NIH or CRDF Global.

\section{References}

1. Brown KM and Arthur JR (2001) Selenium, selenoproteins and human health: a review Public Health Nutr 4(2B) 593-599 https://doi. org/10.1079/PHN2001143 PMID: 11683552

2. Wrobel JK, Power R, and Toborek M (2016) Biological activity of selenium: revisited IUBMB Life 68(2) 97-105 https://doi.org/10.1002/ iub.1466

3. Boosalis MG (2008) The role of selenium in chronic disease Nutr Clin Pract 23(2) 152-160 https://doi.org/10.1177/0884533608314532 PMID: 18390782

4. Combs GF Jr (2001) Selenium in global food systems Br J Nutr 85(5) 517-547 https://doi.org/10.1079/BJN2000280 PMID: 11348568

5. Ferlay J, Ervik M, and Lam F, et al (2020) Global Cancer Observatory: Cancer Today. (Lyon: International Agency for Research on Cancer) https://gco.iarc.fr/today Date accessed: 16/3/21

6. Kayamba V (2021) Nutrition and upper gastrointestinal cancers: an overview of current understandings Semin Cancer Biol S1044$579 \times(21) 00055-9$

7. Vahid F and Davoodi SH (2021) Nutritional factors involved in the etiology of gastric cancer: a systematic review Nutr Cancer 73(3) 376-390 https://doi.org/10.1080/01635581.2020.1756353 
8. Lin Y, Wu C, and Yan W, et al (2020) Five serum trace elements associated with risk of cardia and noncardia gastric cancer in a matched case-control study Cancer Manag Res 12 4441-4451 https://doi.org/10.2147/CMAR.S250592 PMID: 32606938 PMCID: 7293905

9. Hashemi SM, Mashhadi M, and Moghaddam AA, et al (2017) The relationship between serum selenium and zinc with gastroesophageal cancers in the Southeast of Iran Indian J Med Paediatr Oncol 38(2) 169-172 PMID: 28900326 PMCID: 5582555

10. Hosseini Nezhad Z, Darvish Moghaddam S, and Zahedi MJ, et al (2015) Serum selenium level in patients with gastric non-cardia cancer and functional dyspepsia Iran J Med Sci 40(3) 214-218 PMID: 25999620 PMCID: 4430882

11. Egnell M, Fassier P, and Lécuyer L, et al (2017) Antioxidant intake from diet and supplements and risk of digestive cancers in middle-aged adults: results from the prospective NutriNet-Santé cohort Br J Nutr 118(7) 541-549 https://doi.org/10.1017/S0007114517002392 PMID: 28927476

12. Walker EV, Girgis S, and Yuan Y, et al (2021) Community-driven research in the canadian arctic: dietary exposure to methylmercury and gastric health outcomes Int J Circumpolar Health 80(1) 1889879 https://doi.org/10.1080/22423982.2021.1889879 PMID: 33646085 PMCID: 7928021

13. Tan S, Mo J, and Zhang Z, et al (2019) Sodium selenite accentuates the therapeutic effect of adriamycin prodrug (PADM) against gastric cancer Biomed Res Int 20192035682 https://doi.org/10.1155/2019/2035682 PMID: 31737654 PMCID: 6815643

14. Wu B, Ge J, and Zhang Z, et al (2019) Combination of sodium selenite and doxorubicin Prodrug Ac-Phe-Lys-PABC-ADM affects gastric cancer cell apoptosis in xenografted mice Biomed Res Int 20192486783 https://doi.org/10.1155/2019/2486783 PMCID: 6720824

15. Hurst R, Siyame EW, and Young SD, et al (2013) Soil-type influences human selenium status and underlies widespread selenium deficiency risks in Malawi Sci Rep 31425 https://doi.org/10.1038/srep01425 PMID: 23478344 PMCID: 3594796

16. Vinceti M, Filippini T, and Del Giovane C, et al (2018) Selenium for preventing cancer Cochrane Database Syst Rev 1(1) CD005195 PMID: 29376219 PMCID: $\underline{6491296}$

17. Cai X, Wang C, and Yu W, et al (2016) Selenium exposure and cancer risk: an updated meta-analysis and meta-regression Sci Rep 6 19213 https://doi.org/10.1038/srep19213 PMID: 26786590 PMCID: 4726178

18. Safarzad M, Besharat S, and Salimi S, et al (2019) Association between selenium, cadmium, and arsenic levels and genetic polymorphisms in DNA repair genes (XRCC5, XRCC6) in gastric cancerous and non-cancerous tissue J Trace Elem Med Biol 55 89-95 https://doi. org/10.1016/j.jtemb.2019.06.003 PMID: 31345372

19. Kayamba V, Zyambo K, and Mulenga C, et al (2020) Biomass smoke exposure is associated with gastric cancer and probably mediated via oxidative stress and DNA damage: a case-control study JCO Glob Oncol 6 532-541 https://doi.org/10.1200/GO.20.00002 PMID: 32228314 PMCID: 7113078

20. Mayo Clinic Laboratories [https://www.mayocliniclabs.com/test-catalog/Clinical+and+Interpretive/9765] Date accessed: 24/3/21

21. Ritchie H and Roser M (2017) Micronutrient Deficiency Published online at OurWorldlnData.org [https://ourworldindata.org/micronutrient-deficiency] Date accessed: 19/3/21

22. Phiri FP, Ander EL, and Bailey EH, et al (2019) The risk of selenium deficiency in Malawi is large and varies over multiple spatial scales Sci Rep 9(1) 6566 https://doi.org/10.1038/s41598-019-43013-z PMID: 31024041 PMCID: 6484074

23. Joy EJM, Kumssa DB, and Broadley MR et al (2015) Dietary mineral supplies in Malawi: spatial and socioeconomic assessment BMC Nutr 142 https://doi.org/10.1186/s40795-015-0036-4

24. Fairweather-Tait SJ, Bao Y, and Broadley MR, et al (2011) Selenium in human health and disease Antioxid Redox Signal 14(7) 1337-1383 https://doi.org/10.1089/ars.2010.3275

25. Belhadj M, Kazi Tani LS, and Dennouni Medjati N, et al (2020) Se Status prediction by food intake as compared to circulating biomarkers in a West Algerian population Nutrients 12(12) 3599 https://doi.org/10.3390/nu12123599 PMCID: 7760749 
26. Ashton K, Hooper L, and Harvey LJ, et al (2009) Methods of assessment of selenium status in humans: a systematic review Am J Clin Nutr 89(6) 2025S-2039S https://doi.org/10.3945/ajcn.2009.27230F PMID: 19420095

27. Phiri FP, Ander EL, and Lark RM, et al (2020) Urine selenium concentration is a useful biomarker for assessing population level selenium status Environ Int 134105218 https://doi.org/10.1016/j.envint.2019.105218

28. Kayamba V, Asombang AW, and Mudenda V, et al (2013) Gastric adenocarcinoma in Zambia: a case-control study of HIV, lifestyle risk factors, and biomarkers of pathogenesis S Afr Med J 103(4) 255-259 https://doi.org/10.7196/SAMJ.6159 PMID: 23547703 PMCID: 3815678

29. Camargo MC, Burk RF, and Bravo LE, et al (2008) Plasma selenium measurements in subjects from areas with contrasting gastric cancer risks in Colombia Arch Med Res 39(4) 443-451 https://doi.org/10.1016/j.arcmed.2007.12.004 PMID: 18375257 PMCID: 2394852

30. Hu A, Li L, and Hu C, et al (2018) Serum concentrations of 15 elements among Helicobacter Pylori-infected residents from Lujiang County with high gastric cancer risk in Eastern China Biol Trace Elem Res 186(1) 21-30 https://doi.org/10.1007/s12011-018-1283-4 PMID: 29502251

31. Wu MC, Huang CY, and Kuo FC, et al (2014) The effect of Helicobacter pylori eradication on the levels of essential trace elements Biomed Res Int 2014513725 PMID: 25548772 PMCID: 4274842

32. Shreenath AP, Ameer MA, and Dooley J (2021) Selenium Deficiency (Treasure Island: StatPearls Publishing)

33. Thomson C (2004) Assessment of requirements for selenium and adequacy of selenium status: a review Eur J Clin Nutr 58 391-402 https://doi.org/10.1038/sj.ejcn.1601800 PMID: 14985676 